\title{
Economics
}

\section{Determinants of Access to Formal Credit in Rural Areas of Ethiopia: Case Study of Smallholder Households in Boloso Bombbe District, Wolaita Zone, Ethiopia}

\author{
Samuel Semma Waje \\ Wolaita Zone Food Security Department, Wolaita Sodo, Ethiopia
}

Email address:

samuelsemma4@gmail.com

\section{To cite this article:}

Samuel Semma Waje. Determinants of Access to Formal Credit in Rural Areas of Ethiopia: Case Study of Smallholder Households in Boloso Bombbe District, Wolaita Zone, Ethiopia. Economics. Vol. 9, No. 2, 2020, pp. 40-48. doi: 10.11648/j.eco.20200902.13

Received: May 28, 2020; Accepted: June 9, 2020; Published: June 29, 2020

\begin{abstract}
The majority of agricultural production in Ethiopia is carried out by smallholder farmers. Improving food security in short run and poverty in the long run has remained to be the major challenges in Sub-Saharan Africa countries especially in Ethiopia. This study required to identify determinants that limit smallholder households' access to formal credit in the Boloso Bombbe District, South Region of Ethiopia. The study utilized cross sectional survey research design to attain the objectives. Primary and secondary data were used and analyzed by using STATA Version 14. Sample size determined by using Cochran formula and 312 households selected using multistage sampling techniques. Probit regression model was used to analyze quantitative data. The results shows that credit access was determined by the variables like Age, educational level of the smallholders, membership, extension service, saving habit, collateral, connection with local leaders and livelihood diversification. Output of the study revealed that only $36.54 \%$ of the respondents in the study area had accessed formal credit while $63.46 \%$ did not have any access to credit. This calls the government and non - governmental organizations have to be done more in credit access to improve the future productivity of smallholder agriculture in Ethiopia.
\end{abstract}

Keywords: Determinants, Credit Access, Smallholders', Probit Regression Model, Ethiopia

\section{Introduction}

Access to credit is an integral part of rural smallholders' lives in order to activate income generating activities and in long run reduce poverty in developing countries [2]. Many researches tend to focus on developing countries like African firms and rural credit markets in Asia especially in India. Akoten, 2006 [1] and Pal, 2002 [24] focused their empirical analysis on credit constraints and it has significant policy implications as the welfare of households can be better examined if those who are credit constrained can be properly identified.

Low access to credit by smallholder farmers who are the majority of the sector drivers is among the major constraining factors [14]. Agricultural credit is an essential element for agricultural growth in developing countries [18]. It is a temporary substitute for personal savings and it accelerates technology change to stimulate agricultural production by enhancing smallholder farmers' productivity, asset formation, and food security and subsequently, rural agricultural income In India and Brazil, for example, agricultural financing is given very high priority. The World Bank through its private financing arm, International Finance Corporation (IFC), among other banks has also promoted agricultural credit [33]. The availability of formal finance to the smallholder farmers is essential, if they are to produce a marketable surplus and thereby contribute to the development process [33].

Enhancing financial sector could be a powerful tool to fight poverty. Access to a well-functioning financial system can empower individuals both economically and socially, allowing the smallholders to integrate more successfully into the economy of their countries, actively contribute to their development, and protect themselves against economic shocks 
[30].

It is important to understand that the meaning of credit access and smallholder farmers. According to Penchansky R. and Thomas W. J., (1981) [26], credit access refers to "entry into or use of the health care system, while to others it characterizes factors influencing entry or use." Moreover, according to the free on line dictionary (undated), access can be defined as, the right to obtain or make use of or take advantage of something (as services or membership). Access to financial services by smallholders is normally seen as one of the constraints limiting their benefits from credit facilities. However, in most cases the access problem, especially among formal financial institutions, is one created by the institutions mainly through their lending policies [12]. Smallholder farmers also could be defined as "those farmers owning small-based plots of land on which they grow subsistence crops and one or two cash crops relying almost exclusively on family labor". Smallholder farmers differ from the rest of farmers in the agriculture sector in terms of their limited resources. Smallholder farmers in Su Saharan Africa utilize simple and outdated agricultural technologies and cultivate small plots of land [12].

The major challenge of developing countries especially in Sub-Saharan Africa was poverty [15]. It has also been long established that more than $75 \%$ of the world's poor reside in rural areas and will continue to do so well into the $21 \mathrm{st}$ century. People in rural areas lack not only economic opportunities; they also have less access to social services such as health, information, water, sanitation and education [15]. In fact, agriculture continues to be the backbone of rural economies across the world and is one the key instrument to rural poverty alleviation (World Bank 2008). Improving agricultural productivity could be critical in reducing rural poverty [5]. Enhancing access to appropriate credit services among resource-poor people has been increasingly considered as one means of tackling poverty. Access to credit helps farmers to acquire necessary farm inputs and technologies, make strategic investments in their farms, exploit opportunities by undertaking value adding activities, and in terms of accessing better market opportunities that fetch them higher return. Agriculture heavily depends on credit more than any other sector because of the seasonal variations in the farm income and a move towards commercial farming [30].

Empirically, to see some related literatures access to formal credit can also be affected by household characteristics. Kiplimo et al 2015 [19] analyzed the determinants of Access to Credit Financial Services by Smallholder Farmers in Kenya, concluded that education level, occupation and access to extension services were statistically significant with positive effects on access to credit financial services. In addition, Assogba et al 2017 [25] described the determinants of credit access by smallholder farmers in North-East Benin, analyzed that access to credit among smallholder farmers is determined by the number of years of schooling, literacy, membership, guarantor, collateral and interest rate. Kedir, 2007 [18] determinants of
Access to Credit and Loan Amount: Household-level Evidence from Urban Ethiopia, he found that geographical location of households, current household resources, schooling of the household head, value of assets, collateral, number of dependants, marital status and outstanding debt as significant factors. [18]. Assogba, 2017 [25] identified a set of socio-economic, physical and psychological factors that influence credit use among small farmers with a view to differentiate between borrowers, potential borrowers, and non-borrowers. The results of the study indicated that borrowers were characterized by higher resource base, farm size, higher level of education, large number of cattle, higher household.

In Ethiopia the rural population, which accounts for about $85 \%$, is in areas where communication and transportation facilities are poorly developed. Ethiopia has one of the lowest road and telephone densities per inhabitant in sub-Saharan Africa. Economic growth performance in Ethiopia over the past few years has been strong and broad-based. Real GDP growth was estimated at $9.6 \%$ in 2006, according to the World Fact Book. After a significant drought-induced contraction, real GDP growth was $8.9 \%$ in $2004 / 05$, following $11.4 \%$ growth rate rebound in $2003 / 04$ [20].

There is a wide gap between owned and required capital to finance the agricultural activities of small holder farmers since the income from subsistence agriculture does not yield much surplus beyond family consumption and other social obligations. Lack of access to capital (credit access) in rural areas is one of the major factors which hinder the development of agriculture [29]. The other determinants which challenge the smallholders are collateral, limited livelihood diversification, low saving account, connection to leaders, membership of any MFIs/Cooperatives, Extension service were the main challenges in accessing formal credit in Rural Areas of Ethiopia. The main objective of this study is empirically to identify the determinants of access to formal rural credit in order to alleviate poverty in Boloso bombbe district in southern Ethiopia.

\subsection{Objectives of the Study}

The study has general and specific objectives.

\subsubsection{General Objective}

The general objective of this study is to identify the determinants of access to formal credit to smallholders in the study area.

\subsubsection{Specific Objectives}

1. To examine socio -economic factors of formal credit access to smallholders farmers in the district.

2. To identify the determinants of access to formal credit in the study area.

\subsection{Hypothesis of the Study}

The researcher developed the of hypothesis

Ho 1: There is significance impact of socio-economic 
factors on the performance of formal credit access to small holders in farmers

Ho 2: There is significant influence of collateral, saving, connection to local leaders, livelihood diversification extension services, interest of households, membership on access to credit of smallholder farmers in the study area.

\section{Methods}

\subsection{The Study Area}

Wolaita zone is located in southern Ethiopia, between $6.4^{\circ}$ $7.1^{\circ} \mathrm{N}$ and $37.40^{\circ}-38.20^{\circ} \mathrm{E}$ geographical position and $360 \mathrm{Km}$ south of Addis Ababa, capital of Ethiopia. The zone is one of the fifteen zonal administrative structures in south regional state of Ethiopia, covering an area of $4471.3 \mathrm{Km}^{2}$ [8]. The zone is divided into sixteen woredas (districts) six town administrations. The total population of the zone is estimated about 1,907,079 with average density 385 inhabitants per square kilometers [8] being is one of densely populated areas in Ethiopia. Boloso Bombbe district is one of sixteen districts found in the wolaitta zone, which is $56 \mathrm{Km}$ far from Sodo City.

\subsection{Target Population}

The study area consists of the total population of 24,562 households in the district [8]. From which 6,203 households were credit accessed and the remaining were not credit accessed households of the study area and only 590 households were accessed to credit and 1070 households were not accessed to credit. The total of 1660 households were selected from five study kebelles (villages). The lists of all credit accessed and not accessed households were registered by Boloso Bombbe District Agricultural Development Office.

\subsection{Sampling Technique}

The researcher used a multi-staged sampling procedure. The first stage, the farmers were grouped according to their accessibility to credit (i.e. Credit users and non users). In stage two, a proportionate sampling procedure was used to determine the number of Smallholder households' to be selected from each of the group based on the sample size. Finally, in stage three, the smallholder households were randomly selected with the use of the balloting system to make up the determined proportion of each category.

Table 1. Sample size determination each study area with credit users non credit users.

\begin{tabular}{|c|c|c|c|c|c|c|}
\hline \multirow{2}{*}{ Villages } & \multicolumn{2}{|c|}{ Credit users } & \multicolumn{2}{|c|}{ Non credit users } & \multirow{2}{*}{ Total households (N) } & \multirow{2}{*}{ Sample size (n) } \\
\hline & Male & Female & Male & Female & & \\
\hline Bombbe 02 & 66 & 82 & 156 & 144 & 448 & 84 \\
\hline Bombbe 01 & 40 & 56 & 124 & 142 & 362 & 68 \\
\hline G/mahber & 56 & 72 & 148 & 120 & 396 & 75 \\
\hline Farawocha & 84 & 66 & 90 & 102 & 342 & 64 \\
\hline Adila & 44 & 24 & 26 & 18 & 112 & 21 \\
\hline
\end{tabular}

Source: Own computation, 2020

\subsection{Sample Size}

To achieve the objectives of the study 5 (five) Kebeles were purposely chosen from the study districts. According to Cochran (1963:75) developed the equation to yield a representative sample for proportions of large sample. Since the numbers of smallholder farmers in the districts are more than 10,000 in the five kebeles, we can use the sample size formula (Cochran 1963:75).

$$
n_{0}=\frac{Z^{2} p q}{e^{2}}
$$

Which is valid where $\mathrm{n}_{0}$ is the sample size, $\mathrm{Z}^{2}$ is the abscissa of the normal curve with $95 \%$ confidence level and $5 \%$ precision ' $\mathrm{e}$ ' is the desired level of precision, $\mathrm{p}$ is the estimated proportion of an attribute by assuming $\mathrm{p}=0.5$ (maximum variability) that is present in the population, and $q$ is $1-p$. The value for $\mathrm{Z}$ is 1.96 which is found in statistical tables which contain the area under the normal curve. By using the above formula, we have;

$$
n o=\frac{Z^{2} p q}{e^{2}}=\frac{(1.96)^{2} * 0.5 * 0.5}{(0.05)^{2}}=\frac{(3.8416) * 0.25}{0.0025}=384
$$

Using infinite population sample size determination formula the total numbers of samples included in the study were $=384$. Since the study targeted five Kebeles smallholders which are registered in district office were less than 10,000 and the study used finite population sample size determination formula (Cochran 1963:75), we have:

$$
\mathrm{n}=\frac{\frac{\mathrm{no}}{1+(\mathrm{no}-1)}}{\mathrm{N}}=\mathrm{n}=\frac{\frac{384}{1+(384-1)}}{1660}=\frac{\frac{384}{1+(383)}}{1660}=\frac{384}{1.2307}=312, \text { Where no }=\text { sample size, } \mathrm{N}=\text { total households }
$$

\subsection{Data Types, Sources and Collections}

The data collection method relied on primary data which has been collected mainly, interviews and open and closed ended questionnaires. Secondary data are: manuals, reports, profiles, and statically data and other national and international reviews. Structured questionnaires were used to collect data on the socio-economic characteristics we considered could affect households' decisions to access credit 
or not. Determinants captured by the questionnaire included age sex, marital status, education, family size, farm size, credit using experience, Annual income, saving culture, collateral, connection, livelihood diversification, and extension services The questionnaires were administered randomly to the three hundred twelve selected households.

\subsection{Data Analysis}

Data were analyzed using descriptive and inferential statistics. Data was analyzed by using STATA software version 14. To achieve the stated objectives Probit regression model was used to analyze quantitative data. Descriptive statistics such as mean, standard deviation and percentage, were used to describe characteristics that can influence performance in credit use which was presented by tabular form. In addition, mean comparison tools were applied between the characteristics of credit users and non- users and chi-square test was used for dummy variables.

\section{Empirical Estimation Method}

\section{The Probit Regression Model}

For dependent variable, Probit regression model can be used as regression model to identify the relationship between the dependent variable and the set of explanatory variables [17]. The probit model was used in this study to examine the determinants that affecting Smallholder farmer's access to credit in Boloso Bombbe district in Ethiopia.

The model is based on the following specification:

$$
Y=f(x)
$$

In this equation, $\mathrm{Y}$ is the dependent variable which represents small holder farmer's access to credit and $\mathrm{X}$ the set of explanatory variables. $\mathrm{Y}$ is equal to 1 , when a farmer does have access to credit; and 0 otherwise.

More explicitly, Equation 2 can be expressed as:

$Y=\beta o+\beta_{1} X_{1}+\beta_{2} X_{2}+\beta_{3} X_{3}+\beta_{4} X_{4}+\beta_{5} X_{5}+\beta_{6} X_{6}+\beta_{7} X_{7}+\beta_{8} X_{8}+\beta_{9} X_{9}+\beta_{10} X_{10}+\beta_{11} X_{11}+\beta_{12} X_{12}+\beta_{13} X_{13}+\beta_{14} X_{14}+\beta_{15} X_{15}+e_{i}$

Where,

i. $\mathrm{Y}=$ dependent variable (Access to credit),

ii. $\beta o=$ Constant term; $X_{1}=$ Sex,$X_{2}=$ Age of the households, $X_{3}=$ Martial status, $X_{4}=$ Education, $X_{5}=$ family size, $X_{6}=$ farm size, $X_{7}=$ Annual income, $X_{8}=$ experience in credit use, $X_{9}=$ interest of borrowers, $X_{10}=$ Membership of MFIs/Cooperatives, $\mathrm{X}_{11}=$ Saving habit, $\mathrm{X}_{12}=$ collateral, $\mathrm{X}_{13}=$ connection to local leaders, $\mathrm{X}_{14}=$ Livelihood diversification, $\mathrm{X}_{15}=$ Extension service and $\mathrm{e}_{\mathrm{i}}=$ Error term were explanatory variables.

iii. $\beta 1-\beta 15$ are the coefficients associated with each independent variables which measure the change in the mean value of access to formal credit.

Table 2. Definitions of Hypothesized Variables and measurements for determinants of access to credit.

\begin{tabular}{|c|c|c|c|}
\hline Variables & Types & Description & $\begin{array}{l}\text { Expected } \\
\text { sign }\end{array}$ \\
\hline \multicolumn{4}{|l|}{ Dependent variables } \\
\hline Access to credit & Dummy: 1 if yes, 0 otherwise & Whether a household head has access to credit or not & \\
\hline \multicolumn{4}{|l|}{ Independent variables } \\
\hline $\operatorname{Sex}(\operatorname{Sex})$ & Dummy: 1 if yes, 0 otherwise & Sex of the household head & + \\
\hline Marital status (Marst) & Dummy: 1 if yes, 0 otherwise & If the household has married or not & + \\
\hline Age (Age) & Continuous (Years) & Age of the Household & - \\
\hline Family size (Famlsz) & Head Count & Number of people live in the HHs & $+/-$ \\
\hline Farm size (farms) & Hectares & The size of total farm in hectares & + \\
\hline $\begin{array}{l}\text { Annual income of the households } \\
\text { (AnIn) }\end{array}$ & Continuous (Income in the year) & The amount of money in Ethiopian money (Birr) & + \\
\hline Household Education (Educ) & $\begin{array}{l}\text { Dummy: } 1 \text { if follow formal education, } \\
0 \text { otherwise }\end{array}$ & Education of the $\mathrm{HH}$ head & + \\
\hline Experience of credit use (Expcruse) & Continuous (Years) & Numbers of years & + \\
\hline Interest to credit (borrowing (INTCR) & Dummy: 1 if yes, 0 otherwise & $\begin{array}{l}\text { Whether a household has interests to borrow from MFIs or } \\
\text { not }\end{array}$ & + \\
\hline Collateral (Coll) & Dummy: 1 if yes, 0 otherwise & $\begin{array}{l}\text { Whether a household has assets that can allow them to } \\
\text { borrow or not }\end{array}$ & - \\
\hline Saving culture (Sav) & Dummy: 1 if yes, 0 otherwise & $\begin{array}{l}\text { Whether a farmer has an account with a financial } \\
\text { institution or not }\end{array}$ & + \\
\hline Livelihood diversification (LIVDIV) & Dummy: 1 if yes, 0 otherwise & $\begin{array}{l}\text { Whether a household is engaged in multiple livelihood } \\
\text { activities or not }\end{array}$ & + \\
\hline Connection to lenders (Conn) & Dummy: 1 if yes, 0 otherwise & $\begin{array}{l}\text { Whether a household head has } \\
\text { relationship with a lender or not }\end{array}$ & + \\
\hline Membership of MFIs (Memb) & Dummy: 1 if yes, 0 otherwise & Whether a farmer is a member of any MFIs or not & + \\
\hline Extension service (ExtSer) & Dummy: 1 if yes, 0 otherwise & $\begin{array}{l}\text { Whether a farmer got extension service from Development } \\
\text { agent or not }\end{array}$ & + \\
\hline
\end{tabular}

Source: Own computation: 2020 


\section{Results and Discussion}

\subsection{Socio-economic Characteristics of the Smallholders' Farmers}

Table 3. Means differences for continuous variables of Credit not accessed and accessed households.

\begin{tabular}{llll}
\hline \multirow{2}{*}{ Variables } & All variables $(\mathbf{N}=\mathbf{3 1 2})$ & Credit Not accessed (N=198) & Credit accessed $(\mathbf{N}=\mathbf{1 1 4})$ \\
\cline { 2 - 4 } & Means & Means & Means \\
\hline Age (Year) & 36.40064 & 34.39899 & 39.87719 \\
Family size (No) & 5.217949 & 5.106061 & 5.412281 \\
Experience in credit use (year) & 1.105769 & .1224747 & 3.026316 \\
Farm size (hectare) & .3372596 & .3286616 & .3526316 \\
Annual Income (in ETB) & 24200.77 & 23542.06 & 25344.84 \\
\hline
\end{tabular}

Source: field survey, 2020.

Table 3 depicts the socio - economic characteristics of the households. It can be seen that those households who have not accessed credit were younger's (mean age of 34 years) than the households who accessed credit (mean age of 40 years). This is because the Microfinance institutions and society accepts the social and cultural value and the economy base of the households. There are no obvious differences with regard to household size. Credit users have one extra household member making their households the largest (mean of 6 persons) as compared to mean of 5 persons over all households and in non- user households.
In terms of experience in credit use, households who gained credit have more experience (mean of 3 years) than that of the households who do not accessed the credit (the mean age of 0.12 years). This simply indicates that credit financiers have more trust and give more recognition for those smallholders who have more experience than those who do not. The farm size of all respondents was nearly equal (mean of 0.33 hectares). The mean of annual income of both credit users and non users were nearly the same i.e. Ethiopian Birr (ETB) $24,200(\$ 780.64)$.

Table 4. Socio-economic factors of formal credit users and non users of for discrete variables.

\begin{tabular}{|c|c|c|c|c|c|}
\hline Variables & Value & $\begin{array}{l}\text { Households not accessed to } \\
\text { credit }(\%)(\mathrm{N}=198)\end{array}$ & $\begin{array}{l}\text { Households accessed to } \\
\text { credit }(\%)(\mathrm{N}=114)\end{array}$ & Ch square $\left(X^{2}\right)$ & P-Value \\
\hline \multicolumn{6}{|c|}{ 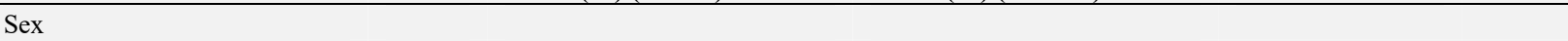 } \\
\hline Male & 0 & $109(55.05)$ & $35(30.70)$ & \multirow{2}{*}{1.846} & \multirow{2}{*}{0.174} \\
\hline Female & 1 & $89(44.95)$ & $79(69.30)$ & & \\
\hline \multicolumn{6}{|l|}{ Marital status } \\
\hline Married & 1 & 8743.94) & $32(28.07)$ & \multirow{3}{*}{17.551} & \multirow{2}{*}{0.000} \\
\hline Unmarried & 0 & $111(56.06)$ & $82(71.93)$ & & \\
\hline \multicolumn{5}{|l|}{ Education } & \\
\hline Formal education & 1 & $56(28.28)$ & $42(36.84)$ & \multirow{3}{*}{43.128} & \multirow{3}{*}{0.000} \\
\hline No formal education & 0 & $142(71.72)$ & $72(63.16)$ & & \\
\hline \multicolumn{4}{|l|}{ Membership of MFIs } & & \\
\hline Yes & 1 & $76(38.38)$ & $47(41.23)$ & \multirow{2}{*}{13.962} & \multirow{2}{*}{0.000} \\
\hline No & 0 & $122(61.62)$ & $67(58.77)$ & & \\
\hline \multicolumn{6}{|l|}{ Customers interest to credit } \\
\hline Yes & 1 & 11457.58 & 7364.04 & \multirow{2}{*}{12.321} & \multirow{2}{*}{0.000} \\
\hline No & 0 & 8442.42 & 4135.96 & & \\
\hline \multicolumn{6}{|l|}{ Saving culture } \\
\hline Yes & 1 & $55(27.78)$ & $52(45.61)$ & \multirow{2}{*}{30.782} & \multirow{2}{*}{0.000} \\
\hline No & 0 & $143(72.22)$ & $62(54.39)$ & & \\
\hline \multicolumn{6}{|l|}{ Extension service } \\
\hline Yes & 1 & $74(37.37)$ & $46(40.35)$ & \multirow{2}{*}{16.615} & \multirow{2}{*}{0.000} \\
\hline No & 0 & $124(62.63)$ & $68(59.65)$ & & \\
\hline \multicolumn{6}{|l|}{ Connection to local leaders } \\
\hline Yes & 1 & $63(31.82)$ & $37(32.46)$ & \multirow[b]{2}{*}{40.205} & \multirow[b]{2}{*}{0.000} \\
\hline No & 0 & $135(68.18)$ & $77(67.54)$ & & \\
\hline \multicolumn{6}{|l|}{ Livelihood diversification } \\
\hline Diversified & 1 & $66(33.33)$ & $46(40.35)$ & \multirow{3}{*}{24.821} & \multirow{3}{*}{0.000} \\
\hline Not diversified & 0 & $132(66.67)$ & $68(59.65)$ & & \\
\hline \multicolumn{4}{|l|}{ Collateral } & & \\
\hline HHs who have collateral & 1 & $40(20.20)$ & $24(21.05)$ & \multirow{2}{*}{108.513} & \multirow{2}{*}{0.000} \\
\hline HHs who have no collateral & 0 & $158(79.80)$ & $90(78.95)$ & & \\
\hline
\end{tabular}

Note: *** represent significant at $1 \%$.

Source: Computed from field survey data, 2020.

Table 4 shows the descriptive statistics of smallholders' households' access to formal credit access. The results of the 
study point out that only $36.54 \%$ of the respondents in the study area had accessed formal credit from microfinance institutions while $63.46 \%$ did not have any access to credit. The result shows low level of access to credit for smallholders households in the area (Table 4). The likelihood test ratio statistics indicated by the chi-square statistics is highly significant ( $\mathrm{p}$ value sign $=0.000)$ suggesting strong explanatory power of the model. The socio - economic factors of smallholder households for discrete variables in the study area are in relation to the ten variables that were hypothesized to have consequence on access to formal credit services. This includes; sex, level of education, marital status, Customers interest to credit, saving culture, membership of MFI, extension services and livelihood diversification, connection with local leaders and collaterals.

The analyses of sex shows that those farmers who gained credit were $35(30.70 \%)$ males and $79(69.30 \%)$ were females. On the other hand those households who did not accessed credit were 109 (55.05\%) males and 89 (44.95\%) were females. Chi square test $\left(\mathrm{x}^{2}\right)$ of independence and the value of probability ( $p$ ) showed that there is no statistical relationship between gender and access to credit to formal credit in the study area $\left(\mathrm{x}^{2}=1.846, \mathrm{p}>.174\right)$. This shows that gender is not the criteria to get access to credit whether the farmers were males or females. Moreover, it was found that among those households have not accessed formal credit, 56 (28.28\%) followed formal education and large portion $142(71.72 \%)$ of the smallholders have not followed formal education. On the other hand, among those households have accessed formal credit, 42 (36.84\%) followed formal education 72 (63.16\%) followed informal education. According to the results, the educational level of the respondents between those who accessed credit and those who did not were statistically significantly different at $1 \%$ level of significance as shown by $\mathrm{X}^{2}$ of 43.128 and $\mathrm{P}$-value of 0.000 . This indicates education is one of major determinant for formal credit in the area.

Among the smallholder's the category that do not access credit, $37.37 \%$ contacted the extension services agents and $62.63 \%$ did not access the extension services. On contrary to this, the household who accessed credit, $40.35 \%$ accessed extension services while $68(59.65 \%)$ did not. The results of chi square value of 16.615 and $p$ value 0.000 indicate that there was significant relationship between the credit access to poor households and extension services. The smallholders should gain the technical advice to stick together extension package programs. The study also reveal that among the category of households not accessed to credit, 55 (27.78\%) have saving habit and massive portion 143 (72.22\%) do not have saving culture. On the other hand, among the category of households accessed to credit $45.61 \%$ do not have saving culture and $54.39 \%$ have saving culture. According to this study, the results shows membership of any MFIs, interest of the smallholders', connection to local leaders, livelihood diversification and collateral have significant relationship with credit access with chi square value of $13.962,12.321$, $40.205,24.821108 .513$ and probability value of $p=0.000$. respectively.

According to the first objective of this study, the null hypothesis which describes the socio - economic factors do not have significant impact on the credit access was rejected because the study reveals that the socio - economic factors such as saving, extension service, connection to local leaders, collateral are statistically significant $(\mathrm{p}=0.000)$ at $1 \%$ to credit access of the smallholders.

\subsection{The Model Output}

Table 5. Probit regression model output of determinants of formal credit of smallholders.

\begin{tabular}{|c|c|c|c|c|c|}
\hline Variables & Coef. & Std. Err. & $\mathbf{Z}$ & $\mathbf{P}>|\mathbf{z}|$ & Marginal effect (dy/dx) \\
\hline Sexr & -.2447599 & .2893973 & -0.85 & 0.398 & -.0770323 \\
\hline Martr & .4615665 & .303963 & 1.52 & 0.129 & .1508758 \\
\hline Educr & 1.556849 & .3198458 & 4.87 & $0.000 * * *$ & .5301844 \\
\hline Ager & -.035161 & .0201887 & -1.74 & $0.082 *$ & -.0111521 \\
\hline Farmsize & .6930514 & .8530377 & 0.81 & 0.417 & .2198159 \\
\hline Famsr & -.0078936 & .1332231 & -0.06 & 0.953 & -.0025036 \\
\hline AnnIn & -9.3306 & .0000266 & -0.35 & 0.725 & -2.9606 \\
\hline Cusint & .3072176 & .298831 & 1.03 & 0.304 & .0952151 \\
\hline Collr & 1.222105 & .3575242 & 3.42 & $0.001 * * *$ & .4389574 \\
\hline Livdir & 1.270859 & .3002483 & 4.23 & $0.000 * * *$ & .4261212 \\
\hline Savr & 1.711961 & .3233282 & 5.29 & $0.000 * * *$ & .5697169 \\
\hline Connr & 1.231804 & .3057132 & 4.03 & $0.000 * * *$ & .4209308 \\
\hline Membr & .6078292 & .2740024 & 2.22 & $0.027 * *$ & .1983385 \\
\hline extsert & 1.399143 & .3003815 & 4.66 & $0.000 * * *$ & .4607771 \\
\hline \multicolumn{6}{|c|}{ Diagnostic statistics } \\
\hline Number of obs & & 312 & & & \\
\hline LR chi2 (15) & & 294.54 & & & \\
\hline Prob $>$ chi 2 & & 0.0000 & & & \\
\hline Log likelihood & & -57.545269 & & & \\
\hline Pseudo R2 & & 0.7190 & & & \\
\hline
\end{tabular}

Dependent variable: Access to formal credit $(1=\mathrm{HHs}$ has access; $0=$ otherwise $) . * *$ Significant at $1 \%$, ** significant at $5 \%$ and $*$ significant at $10 \%$ level. Source: Computed from the field survey data, 2020 


\subsection{Determinants Access to Formal Credit of Rural Smallholders}

The Probit regression model result indicates that among 15 hypothesized explanatory variables nine variables were found statistically significantly determine the rural smallholder households' formal credit access at $1 \%, 5 \%$ and $10 \%$ possibility level. From the result it can be seen that credit access was determined $71.9 \%$ by the above mentioned factors (Table 5). The remaining $28.1 \%$ credit access of smallholders was determined by other factors. The likelihood ratio Chi-square of 294.54 with a p-value of 0.000 tells us that our model is statistically significant.

Those variables with positive effects on the smallholders' farmers access to credit include Age, education, experiences on using credit, membership of any Microfinance institutions, livelihood diversification, saving, collateral, connection to local leaders and extension services and age is the only variable that negatively affected the smallholders credit access in the study area.

Age (Age) - The negative relationship age of the households and access to credit is that households with higher age were less likely to get access to credit because old aged smallholder farmers were not expected to recover the amount credit they borrowed. As indicated on table 4, the marginal effect estimation results every one year increase in the age of household heads leads to a $1.1 \%$ decrease in the probability of access to credit. The study relates with the study of Assogba, 2017 [25].

Education (Educ): The model output stated that education (Educ) has positively and significantly determined the household's access to credit process at less than at $1 \%$ probability level. The finding shows that the smallholder farmers who followed formal education are more likely access the credit possibility than those who do not. These is because educated households understand more about credit issues and got information and use it and the MFIs expect that the loan borrowers recover their money timely. From the above table we can see that the model results, the marginal effect reveals the likelihood of a household access to formal credit increased by $53 \%$ i.e. one grade adding can improve the chance of borrowing (accessing credit) by 53 percent. This result is the similar output with various researches (Yisak gecho, 2014 [34] and Assogba et al, 2017 [25].

Experience of credit using (Expcruse): As it is expected, this variable has positive effect on credit access and statistically significant to determine the household's access to credit process at the probability of $10 \%$ probability level. This indicates that the more experienced the households in credit use, the better to get access to formal credit in the study area. The marginal effect estimation indicates that the probability and intensity of credit use of the farmers will be increased by $4.8 \%$ for every one percent increase in the experience of using credit. This result is the similar output with various researches such as Dzadze et al. 2012, [14] Roberts, L. C., 2017, Tesfaye, T. and Worku, W., 2019. [30]
Livelihood diversification (Livdir): As expected, livelihood diversification variable was found positive and has statistically significant influence on credit access with the probability $(\mathrm{p}=0.000)$ at $1 \%$ in the study area. This indicates that the smallholder households applying livelihood diversification activities such as on-farm and off-farm activities. The marginal effect estimation result indicates that the probability and intensity of access to credit increased by $42.6 \%$ for every one percent increase when they diversify (on-farm and off-farm) their livelihood. The finding is consistent with several research findings including Babatunde, 2010, [4] Beneberu A., 2019) [7] show that the significant determinants of income on livelihood.

Saving (Sav): As expected, Saving variable was found positive and has statistically significant influence on credit access with the probability $(\mathrm{p}=0.000)$ at $1 \%$ in the study area. The model indicates that the smallholder households saving culture were highly important and it is pre condition for credit access in the area. From the model result, the marginal effect estimation result indicates that the probability of access to credit increased by $56.9 \%$ for every one person who saves continuously to be accessed the credit. The study output of Gideon Baffoe \& Hirotaka Matsuda (2015) [5], Twumasi et al, 2019 [31] have similar to this study output.

Connection to local leaders (conn): According to the model output, connection to local leaders variable was found positive and has statistically significant influence on credit access with the probability $(\mathrm{p}=0.000)$ at $1 \%$ in the study area. This indicates that the smallholder households have to create direct connection with local leaders to be accessed to credit in the area. From the model result, the marginal effect estimation result indicates that the probability of access to credit increased by $42 \%$ for every one person who wants to be accessed the credit.

In addition, collateral (coll) variable was found positive and statistically significant and one of the determinant that affect the smallholder access to credit of $(p=0.000)$ at $1 \%$ of the probability level. The marginal effect of estimation result shows that if the borrower has collateral, the stallholder can access the credit by $43.8 \%$. The reason to this is there is concern of loan repaying status of a farmer and to assure that the amount of money to be repaid. This research output is consistent with the finding of Dzadze et al. 2012 [14], Assogba et al, 2017) [25].

Extension service of agent to farmers (extserv): According to the model output, extension service was found positive and has statistically significant influence on credit access with the probability of $(p=0.000)$ at $1 \%$ in the study area. This implies that extension service is one of the vital factors that affect credit access in the study area. According to the model result, marginal effect estimation of the variable indicates that as one percent of extension service increased the probability of access to credit increased by $46 \%$. This implies that, an improvement of extension services in the study area will lead to a positive contribution towards accessing credit services in the study area. This research output is consistent with the 
finding of Beck (2007) [6], Dzadze et al. 2012) [14] and (Kiplimo et al, 2015) [19] who noted that extension services play a crucial role in empowering farmers with farming techniques, knowledge and management skills,.

Membership of MFIs (memb): According to the model output, membership was found positive and has statistically significant influence on credit access with the probability of ( $p$ $=0.000)$ at $1 \%$ in the study area. This implies that extension service is one of the vital factors that affect credit access in the study area. According to the model result, marginal effect estimation of the variable indicates that as one percent of extension service increased the probability of access to credit increased by $19.8 \%$. Some researches supported this idea are [34] Yisak gecho, 2014, Chenaa, T. A., 2018 [10], and Kiplimo et al, 2015). [19]

According to the model output, among fifteen variables were insignificant. These variables such as Sex, marital status, farm size, family size, annual income, customers' interest to borrow have no significant impact on the rural smallholder's credit access in the study area with the probabilities of 0.498 , $0.131,0.122,0.277,0.874,0.829, \quad 0.354$ and 0.879 respectively at $10 \%$ level.

From the model output findings, the substitution of the equation (2) becomes

$$
\begin{aligned}
Y= & -2.75-0.24 X_{1}-0.03 X_{2}+0.46 X_{3}+1.55 X_{4}-0.007 X_{5}+0.69 X_{6}-9.33 X_{7}+0.15 X_{8}+ \\
& 0.30 X_{9}+0.60 X_{10}+1.71 X_{11}+1.22 X_{12}+1.71 X_{13}+1.27 X_{14}+1.39 X_{15}+e_{i}
\end{aligned}
$$

Where

$\mathrm{Y}$ is the dependent variable (formal credit access) $\mathrm{X}_{1}-\mathrm{X}_{15}$ is explanatory variables.

According to the equation, taking all factors constant at zero, the credit access of rural smallholder households' will be decreased by 2.75 . From the results we can conclude that, saving variable with $Z$ value of 5.29 , which is the most determining factor and education with $Z$ value of 4.87, is second determinant next to saving. On the other hand age variable with the least $\mathrm{Z}$ value of -1.74 and experience in using credit with $Z$ value 1.80 are the least determining factors in this study.

\section{Conclusions and Recommendations}

\subsection{Conclusions}

Based on the study findings, the researcher has analyzed the determinants of access to credit among smallholder farmers in the Bololso bombbe district, South region, Ethiopia using a Probit regression model. The results of the study pointed out that only $36.54 \%$ of the respondents in the study area had accessed formal credit from microfinance institutions while $63.46 \%$ did not have any access to credit. The result shows low level of access to credit for smallholders households in the area. Among 15 explanatory variables which were hypothesized to affect households access to credit, the significant variables included in the model such as Age of households, educational status of the farmers, experience of using credit, membership of MFIs, connection (linkage) with local leaders, collateral, saving habit, livelihood diversification and extension service to smallholders were significantly the determining factors of smallholders household credit access in the study area. According to the model result credit access was determined $71.9 \%$ by the above mentioned factors. The remaining $28.1 \%$ credit access of smallholders was determined by other factors. In addition, the likelihood ratio Chi-square of 294.54 with a p-value of 0.000 tells us that our model is statistically significant.

\subsection{Recommendations}

Rural smallholder households have get greater access to credit, governments and non-governmental organizations should encourage education to improve the level how to use credit, increase consultation on saving to increase the habit of saving among smallholder farmers, increase the diversifications of their livelihoods, concrete measure has to be taken to reduce connection with local leaders, improve the frequency of contact level of development agents with smallholder farmers.

\section{Acknowledgements}

The author conveys special thanks to my wife Engineer, Senait Feleke Fanta and Boloso Bombbe District Food Security Office staffs and officials for their technical assistance provided during data collection.

\section{References}

[1] Akoten, J. E., Sawada, Y., and K. Otsoka (2006). The determinants of credit access and its impacts on micro and small Enterprises: The case of garment producers in Kenya. Economic Development and Cultural Change 54 (4): 927-944.

[2] Amin, S., Rai, A. S., and Topa, G. (2003). Does microcredit reach the poor and vulnerable? Evidence from northern Bangladesh. Journal of Development Economics 70 (1): 59-82.

[3] Ayele, A. and Goshu, D., 2018. Determinants of microfinance loan utilization by smallholder farmers: The case of Omo Microfinance in Lemo District of Hadiya Zone, Southern Ethiopia. METHODOLOGY, 9 (13).

[4] Babatunde, R. O.; Olagunju, F. I.; Fakayode, S. B. and Adejobi, A. O. 2010. Determinants of participation in offfarm employment among small-holder farming households in Kwara State, Nigeria.

[5] Baffoe, G., Matsuda, H., Nagao, M., \& Akiyama, T. (2014). The Dynamics of Rural Credit and its impacts on Agricultural Productivity: An Empirical Study in Rural Ghana. OIDA International Journal of Sustainable Development, 7 (5), 19-34. Retrieved November 15, 2014, from http://ssrn. com $/$ abstract $=2495848$

[6] Beck T (2007). Financing constraints of SME's in developing countries. Evidence, determinants and solutions. J. Int. Money Fin. 31 (2): 401-441. 
[7] Beneberu A. Wondimagegnhu, Admassu T. Huluka \& Sarah M. Nischalke (2019) Determinants of farm livelihoods of smallholder farmers in Yayu biosphere reserve, SW Ethiopia: a gender disaggregated analysis, Cogent Economics \& Finance, 7: 1,1645583 .

[8] Beuroue of Finance and Economy development office Report, 2017, Ethiopia.

[9] Central statistical Agency (CSA) Report of 2017, Ethiopia.

[10] Chenaa, T. A., Maria, A. G. and Teno, M. N., 2018. Determinants of Access to Credit and Performance of Smallholder Farmers in Kumba Municipality, South West Region of Cameroon. Asian Journal of Agricultural Extension, Economics \& Sociology, pp. 1-12.

[11] Chisasa, J., 2019. Determinants of Access to Bank Credit by Smallholder Farmers: Evidence from South Africa. Academy of Accounting and Financial Studies Journal.

[12] Diagne, A. Zeller, M. and Sharma, M. 2000. Empirical Measurements of Households' Access To Credit And Credit Constraints In Developing Countries: Methodological Issues And Evidence: International Food Policy Research Institute. Washington, D. C. U. S. A.

[13] Denkyirah, E. K., Adu, D. T., Aziz, A. A., Denkyirah, E. K. and Okoffo, E. D., 2016. Analysis of the factors influencing smallholder rice farmers' access to credit in the upper east region of Ghana. Asian Journal of Agricultural Extension, Economics \& Sociology, pp. 1-11.

[14] Dzadze P, Osei Mensah J, Aidoo R, Nurah GK (2012). Factors determining access to formal credit in Ghana: A case study of smallholder farmers in the Abura-Asebu Kwamankese district of central region of Ghana. J. Dev. Agric. Econ. 4 (14): 416-423.

[15] Food and Agriculture Organization of the United Nations (FAO). (2001). Rural Development: some issues in the context of the WTO negotiations on agriculture. FAO, Rome. Retrieved October 15, 2014, from http://www.fao.org/docrep/005/y3733e/y3733e 04.htm

[16] Gebeyehu, L., Emana, B., Mitiku, F. and Ejeta, T. T., 2019. Determinants of Access to Agricultural Credit among Small holder Maize Farmers: The Case of Hababo Guduru District, Horro Guduru Wollega Zone, Ethiopia. International journal of Horticulture, Agriculture and Food science, 3 (3).

[17] Hosmer, D. W. and Lemeshew, S. 2000. Applied Logistic Regression. A Wiley-Inter-science Publication, New York.

[18] Kedir A (2007). Determinants of access to credit and loan amount: Household-level evidence from urban Ethiopia. Working Paper. p. 7: 3 .

[19] Kiplimo et al. Determinants of Access to Credit Financial Services by Smallholder Farmers in Kenya, Journal of Development and Agricultural Economics, Vol. 7 (9), pp. 303-313, September, 2015.
[20] Martina Wiedmaier Pfister et al.,(2008) Access to finance in Ethiopia, Sector assessment study Volume 2.

[21] Mersha, D. and Ayenew, Z., 2017. Determinants of Access to Formal Financial Sources of Micro and Small Enterprises (MSEs) in West Oromia Region, Ethiopia. International Journal of Business and Economics Research, 6 (5), p. 100.

[22] Mitra, S., Prodhan, M. and Haque, M., 2018. Factors determining credit access of tomato farmers in a selected area of Bangladesh. National Journal of Multidisciplinary Research and Development, 3 (1), pp. 406-410.

[23] Onogwu, G. O., Audu, I. A. and Igbodor, F. O., 2017. Factors influencing agricultural productivity of smallholder farmers in Taraba State, Nigeria. International Journal of Agriculture Innovations and Research, 6 (1), pp. 114-118.

[24] Pal, S. (2002). Household sectoral choice and effective demand for rural credit in India. Applied Economics 34 (14): 1743-1755.

[25] Perceval N. Assogba et al (2017) Determinants of credit access by smallholder farmers in North-East Benin, academic journals, Vol. 9 (8), pp. 210-216, August 2017.

[26] Penchansky, R. and Thomas, W. J., 1981. The Concept of Access: Definition and Relationship to Consumer Satisfaction.

[27] Roberts, L. C., 2017. An Analysis of Determinants of Access to and Use of Credit by Smallholder Farmers in Suakoko District, Liberia (Doctoral dissertation, University of Nairobi).

[28] Sekyi, S., Abu, B. M. and Nkegbe, P. K., 2017. Farm credit access, credit constraint and productivity in Ghana. Agricultural Finance Review.

[29] Sisay, Y. (2008) determinants of small holder farmers access to formal credit in the case of metema woreda.

[30] Tesfaye, T. and Worku, W., 2019. Determinants of Access to Credit Among Small Scale Irrigation User Farmers in Dangla Woreda, Amhara National Regional State, Ethiopia.

[31] Twumasi, M. A., Jiang, Y., Danquah, F. O., Chandio, A. A. and Agbenyo, W., 2019. The role of savings mobilization on access to credit: a case study of smallholder farmers in Ghana. Agricultural Finance Review.

[32] Xueping, X., BI, T. B. A. Y., Traoré, L., Ahiakpa, J. K. and Olounlade, O. A., 2020. Determinants of smallholder farmers' access to microfinance credits. Agricultural Finance Review.

[33] World Bank. 2008. World Development Report. Agriculture for Development, Washington.

[34] Yishak Gecho, Gezahegn Ayele, Tesfaye Lemma, Dawit Alemu. Rural Household Livelihood Strategies: Options and Determinants in the Case of Wolaita Zone, Southern Ethiopia. Social Sciences. Vol. 3, No. 3, 2014, pp. 92-104. 